\title{
Studi Pengaruh Silinder Pori Pada Saluran Drainase Terhadap Debit Infiltrasi
}

\section{Pada Tanah Lempung}

\author{
Fenti Daud Sindagamanik ${ }^{1}$, Sukmasari Antaria $^{2}$, Nenny $^{3}$ \\ 1,2,3 Jurusan Sipil, Fakultas Teknik, Universitas Muhammadiyah Makassar
}

\begin{abstract}
Abstrak
Usaha penanggulangan banjir perlu dilakukan secara dini, dimana salah satunya adalah melakukan perbaikan pada sistim drainase. Penanggulangan banjir memerlukan desain drainase efektif, berwawasan lingkungan, yang berfungsi menampung, dan mengalirkan air dari badan jalan ke lapisan tanah yang ada di bawahnya . penelitian skala laboratorium sangat diperlukan untuk mengetahui : dimensi, rasio luas, bahan dan kedalaman lubang pori yang efektif untuk meresapkan air dari badan saluran drainase ke lapisan tanah di bawah saluran. Penelitian ini dilakukan dengan Studi eksperimental dengan menggunakan model saluran drainase bersilinder pori. Pengujian dilakukan dengan 3 variasi diameter lubang, ,3 variasi ketinggian muka air di saluran. Sebagai media infiltrasi digunakan tanah jenis Lempung yang dimodelkan berdasarkan sampel tanah yang diambil pada lokasi yang sering mengalami banjir atau genangan . Dari pengamatan dan uji laboratorium diharapkan dapat di hasilkan dimensi silinder pori yang seseuai dengan kondisi tanah Lempung pada bagian bawah saluran drainase. Makalah ini merupakan bagian dari penelitian Saluran Bersilinder Pori Berwawasan Lingkungan Pereduksi Genangan banjir Perkotaan, yaitu mengenai Pengaruh Silinder Pori Terhadap debit Infiltrasi Pada Tanah Lempung.
\end{abstract}

Kata kunci : berpori, infiltrasi, saluran, silinder

\section{Pendahuluan}

Hampir setiap musim hujan terjadi banjir di Kota Makassar, serta kota kota besar lainnya di Indonesia. Berbagai media massa melaporkan kejadian tersebut. Badan Nasional Penanggulangan Bencana (BNPB) di Kota ini sudah mengevakuasi sedikitnya 1.500 warga yang berdomisili di Kecamatan Manggala terutama di Perumnas Antang (Tempo, 2013).

Akibat banjir tersebut, beberapa jalan utama di Makassar digenangi air hingga beberapa hari. Jalan utama yang menjadi langganan banjir adalah; Sungai Saddang Baru, Pelita Raya, Urip Sumoharjo, AP Pettarani, Boulevard, Abd Daeng Sirua, Toddopuli, Tidung, Tamalate, Rappocini, Jalan Landak Baru, dan kawasan lainnya. Banjir dapat terjadi sebagai akibat drainase yang tidak memadai sehingga kurang mampu menampung debit air. Disamping itu, minimnya ruang terbuka hijau sebagai areal resapan air, sebagaimana Lapangan Karebosi, yang awalnya diperuntukkan sebagai kawasan resapan air, kini menjadi mall di bawah tanah. Penyebab lainnya adalah drainase dialih fungsikan warga sebagai tempat pembuangan sampah, sehingga saluran tersumbat. Upaya penanganan banjir di kota Makassar tidak akan dapat menuntaskan persoalan jika hanya berputar pada upaya periferal pembersihan dan penggalian sedimen di saluran dan kanal. Hal ini dikarenakan karena jaringan dan dimensi saluran drainase kota ini sudah tidak memadai untuk melayani perkembangan kota yang semakin pesat. Apalagi sistem drainase kota yang dibuat tahun 1985 ini selama hampir 30 tahun tidak diperbaharui, meskipun pada tahun 2004 sempat dibuat masterplannya. Sistem drainase di Makassar sudah perlu dibenahi secara total karena selama ini kita menggunakan sistem drainase lama yang sudah tidak sesuai dengan perkembangan pembangunan.Konsep drainase konvensional yg mengalirkan air buangan secepatnya ke hilir perlu direvisi dgn mengalirkan secara alamiah (lambat), sehingga tdk menimbulkan banjir di hilir. (Kimpraswil, 2006).

Perlu adanya desain saluran drainase efektif, berwawasan lingkungan, yang bukan hanya berfungsi menampung dan mengalirkan air dari badan jalan tetapi sekaligus berfugsi sebagai media penyerapan air ke lapisan tanah yang ada di bawahnya. Hal ini diperlukan sebagai salah satu langkah preventif untuk mencegah debit air yang mengalir ke dalam bangunan saluran drainase melebihi kapasitas maksimum yang telah direncanakan. Salah satu cara yang dapat digunakan untuk meresapkan air tersebut adalah dengan membuat lubang pori atau lubang resapan di sepanjang bagian dasar saluran. Olehnya itu direncanakan untuk mengadakan penelitian skala laboratorium untuk mengetahui; jumlah, dimensi, bahan, dan jarak silinder pori yang efektif untuk meresapkan air dari badan saluran drainase ke lapisan tanah jenis Lempung Liat di bawah saluran drainase.

Hasil Penelitian ini diharapkan dapat digunakan sebagai masukan bagi Pemkot Makassar 
dan Pemerintah di kota- kota lainnya di Indonesia yang setiap tahun dilanda banjir.

\section{METODOLOGI}

\subsection{Desain Penelitian}

Model Saluran Drainase Bersilinder Pori digunakan sebagai alat untuk uji laboratorium, Sebagai media infiltrasi digunakan tanah sampel sesuai tanah di daerah lokasi sampel yang sering mengalami genangan banjir. Penelitian ini menggunakan tiga variabel bebas yaitu, tinggi silinder pori, debit aliran. dan jarak silinder pori masing masing dengan 3 (tiga) variasi. Sedangkan variabel terikatnya adalah debit infiltrasi .

\subsection{Prosedur Pelaksanaan Penelitian}

\subsubsection{Persiapan Bahan dan Alat}

Material untuk pembuatan Model Saluran Drainase Bersilinder Pori, dipersiapkan yaitu Acrilyc, besi , lem acrilyc serta peralatan yang diperlukan antara lain gurinda, alat pemotong acilyc dan lain lain.

\subsubsection{Pembuatan Pintu Thomson.}

Debit air yang masuk ke model saluran diatur dengan menggunakan alat ukur peluap Thompson yang ditempatkan di bagian hilir bak penenang. Alat ukur ini berupa peluap ambang tipis berbentuk segi tiga dengan sudut $90^{\circ}$.

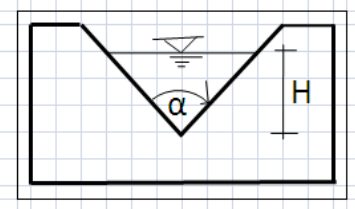

Gambar 1. Pintu Thomson (Triatmodjo B, 1996)

Besarnya debit yang melewati pintu Thomson dihitung dengan rumus :

$$
Q=\frac{8}{15} C_{d} \operatorname{tg} \frac{\alpha}{2} \sqrt{2 g} H^{5 / 2}
$$

dimana :

$\mathrm{Q}=$ debit aliran (1/dtk)

$\mathrm{C}_{d}=$ Koefisien pengaliran, akan diperoleh dari hasil percobaan pada pintu Thomson.

$\alpha=$ sudut peluap segitiga

$\mathrm{g}=$ percepatan gravitasi

$\mathrm{H}=$ tinggi air pada pintu Thomson

Penentuan koefisien pengaliran debit dilakukan dengan pengamatan debit aliran melalui pintu Thomson. Pengamatan dilakukan berulang, sehingga dari pengamatan ini besarnya koefisien pengaliran $C_{d}$ dapat dihitung, seperti pada Tabel 1. di bawah ini.
Tabel 1. Penentuan Koefisien pengalihan debit $C_{d}$

\begin{tabular}{|c|c|c|c|c|}
\hline No & Tingge air $(\mathrm{h})$ & Waktu & $\operatorname{Debit}(Q)(\mathrm{m} / 300 \mathrm{det})$ & Keterangan \\
\hline 1 & 0,035 & 300 & 127000 & \\
\hline 2 & 0,035 & 300 & 127800 & \\
\hline 3 & 0,035 & 300 & 127000 & \\
\hline 4 & 0,035 & 300 & 128100 & \\
\hline 5 & 0,035 & 300 & 129000 & \\
\hline & \multicolumn{2}{|c|}{ Q rata-rata } & $\begin{array}{c}127780 \mathrm{~m} / 300 \mathrm{det} \\
0.000426 \mathrm{~m}^{3} / \mathrm{det}\end{array}$ & \\
\hline
\end{tabular}

$$
\begin{aligned}
& Q=\frac{8}{15} C_{d} \operatorname{tg} \frac{\alpha}{2} \sqrt{2 \mathrm{~g}} H^{5 / 2} \\
& C_{d}=\frac{0.000426 \times 15}{8 \times \operatorname{tg} 45^{\circ} \sqrt{2 \mathrm{~g}} 0,035^{5 / 2}}=0,787
\end{aligned}
$$

Untuk

$\mathrm{Q} 1=2,5 \mathrm{~L} / \mathrm{d}=0,0025 \mathrm{~m}^{3} / \mathrm{d}$ maka $\mathrm{H} 1=7,1 \mathrm{~cm}$

$\mathrm{Q} 2=1,5 \mathrm{~L} / \mathrm{d}=0,0015 \mathrm{~m}^{3} / \mathrm{d}$ maka $\mathrm{H} 2=5,8 \mathrm{~cm}$

$\mathrm{Q} 3=0,4 \mathrm{~L} / \mathrm{d}=0,0004 \mathrm{~m}^{3} / \mathrm{d}$ maka $\mathrm{H} 3=3,5 \mathrm{~cm}$

\subsubsection{Pembuatan Tanah Sampel Untuk Media Infiltrasi}

Tanah sampel yang akan digunakan sebagai media infiltrasi dibuat model tanah jenis Lempung, berdasarkan tekstur tanah lokasi sampel yang dipilih yang sering mengalami genangan banjir .

\subsection{Analisis Data}

Analisis data dilakukan untuk mendapatkan gambaran yang jelas hubungan antara variabel bebas dan variabel terikat hasil dari uji laboratorium. Debit infiltrasi Model Saluran Drainase Bersilinder Pori diperoleh berdasarkan uji laboratorium dengan variasi kedalaman silinder pori, jarak silinder pori.

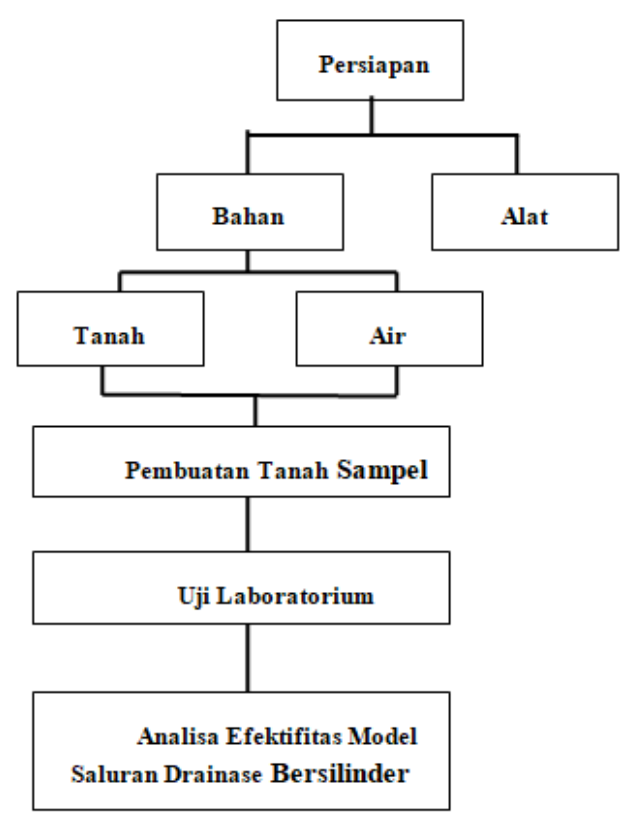

Gambar 2. Bagan Alir Penelitian Tahun I 


\section{HASIL DAN PEMBAHASAN}

\subsection{Hasil yang Dicapai}

\subsubsection{Tekstur Tanah Sampel}

Sebagai media infiltrasi digunakan tanah sampel Lempung Liat dengan tekstur yang sesuai dengan tekstur tanah lokasi sampel (daerah Perintis Kemerdekaan). Hasil pemeriksaan tekstur tanah sampel yang diambil, terdiri dari Pasir $50 \%$, Debu $30 \%$ dan Liat $20 \%$. Berat Jenis tanah sampel 1,544 $\mathrm{gr} / \mathrm{cm}^{3}$

Klasifikasi pasir , debu, dan liat ditentukan berdasarkan pembagian ukuran fraksi fraksi tanah (tekstur) menurut Sistem Departemen Pertanisn Amerika Serikat (USDA) Tahun 1938.

Tabel 2. Diameter Fraksi Partikel Tanah

\begin{tabular}{lc}
\hline Partikel & Diameter Fraksi (mm) \\
\hline Pasir Sangat Kasar & $2,00-1,00$ \\
Pasir Kasar & $1,00-0,50$ \\
Pasir Sedang & $0,50-0,25$ \\
Pasir Halus & $0,25-0,10$ \\
Pasir Sangat Halus & $0,10-0,05$ \\
Debu & $0,05-0,002$ \\
Liat & Kurang dari 0,002 \\
\hline
\end{tabular}

Berdasarkan berat jenis sampel maka jumlah tanah yang digunakan untuk masing masing variasi pengaliran adalah sebagai berikut:

Tabel 3. Berat Tanah yang dibutuhkan untuk uji laboratorium

\begin{tabular}{|c|c|c|c|c|}
\hline No & Diameter $(\mathrm{cm})$ & Keadalaman $(\mathrm{cm})$ & Jarak Lubang $(\mathrm{cm})$ & $\begin{array}{c}\text { Berat Tanah Yang } \\
\text { Dibutuhkan (g) }\end{array}$ \\
\hline 1 & & & 16 & 550410.06 \\
\hline 2 & & 10 & 32 & 552737.18 \\
\hline 3 & & & 48 & 553512.88 \\
\hline 4 & & & 16 & 553803.77 \\
\hline 5 & 8 & 15 & 32 & 554676.44 \\
\hline 6 & & & 48 & 554967.33 \\
\hline 7 & & & 16 & 544980.12 \\
\hline 8 & & 20 & 32 & 549634.36 \\
\hline 9 & & & 48 & 551185.77 \\
\hline
\end{tabular}

\subsubsection{Pembuatan Model Saluran Drainase Bersilinder Pori}

Untuk uji laboratorium digunakan Model Saluran Drainase Bersilinder Pori yang berukuran $(40 \times 40 \times 240) \mathrm{cm}$ serta wadah $(50 \times 50 \times 240) \mathrm{cm}$ yang akan diisi tanah Lempung Liat setinggi $30 \mathrm{~cm}$ sebagai media infiltrasi.Tanah pada wadah ini memiliki lubang yang berisi pasir dengan 3 variasi kedalaman yaitu $5 \mathrm{~cm}, 10 \mathrm{~cm}$ dan $15 \mathrm{~cm}$.

\subsubsection{Infiltrasi Yang Terjadi Akibat Silinder Pori Saluran Drainase Pada Jenis Tanah Lempung .}

Dari hasil uji laboratorium dengan menggunakan Model Saluran drainase bersilinder Pori diperoleh hasil, seperti yang disajikan pada table 4.
Tabel 4. Data Debit Infiltrasi Yang terjadi Pada Saluran Drainase Bersilinder Pori

\begin{tabular}{c|c|c|c|c}
\hline $\begin{array}{c}\text { Tinggi } \\
\text { Silinder } \\
\text { Pori ( } \mathrm{cm} \text { ) }\end{array}$ & $\begin{array}{c}\text { Debit } \\
\text { Pengaliran } \\
\text { (m3/det) }\end{array}$ & \multicolumn{3}{c}{$\begin{array}{c}\text { Debit Infiltrasi (ml/det) Berdasarkan } \\
\text { Jarak Silinder Pori (cm) }\end{array}$} \\
\hline \multirow{3}{*}{15} & 0.0004 & 4.002 & 7.006 & 8.503 \\
\hline \multirow{3}{*}{10} & 0.0015 & 3.978 & 6.584 & 8.393 \\
\hline \multirow{3}{*}{5} & 0.0025 & 3.754 & 6.372 & 8.169 \\
\hline \multirow{3}{*}{5} & 0.0004 & 3.727 & 6.371 & 8.094 \\
\hline & 0.0015 & 3.698 & 6.372 & 8.017 \\
\hline & 0.0025 & 3.673 & 6.286 & 7.649 \\
\hline \multirow{3}{*}{5} & 0.0004 & 3.632 & 6.144 & 7.266 \\
\hline & 0.0015 & 3.628 & 6.052 & 6.863 \\
\hline & 0.0025 & 3.508 & 5.902 & 5.215 \\
\hline
\end{tabular}

\section{Faktor Faktor Yang Berpengaruh Terhadap Debit Infiltrasi}

Pada Gambar (4), (5) dan (6) memperlihatkan faktor yang berpengaruh terhadap debit infiltrasi pada Saluran Drainase Bersilinder Pori antara lain tinggi silinder pori $\left(\mathrm{h}_{1}=5 \mathrm{~cm}, \mathrm{~h}_{2}=10 \mathrm{~cm}\right.$ dan $\mathrm{h}_{3}=$ $15 \mathrm{~cm}$ ) dimana pada gambar (4) menunjukkan debit infiltrasi terbesar yaitu $4.002 \mathrm{ml} / \mathrm{det}$, gambar (5) menunjukkan debit infiltrasi terbesar yaitu 7.006 $\mathrm{ml} /$ det dan gambar (6) menunjukkan debit infiltrasi terbesar yaitu $8.503 \mathrm{ml} /$ det. Faktor lain yang mempengaruhi debit infiltrasi pada Saluran Drainase Bersilinder Pori adalah debit pengaliran dimana pada gambar (4), (5) dan (6) juga nampak jelas peningkatan debit infiltrasi pada Saluran drainase Bersilinder Pori sangat signifikan dengan peningkatan debit pengaliran $\left(\mathrm{Q}_{1}, \mathrm{Q}_{2}\right.$ dan $\left.\mathrm{Q}_{3}\right)$

Selain faktor debit pengaliran dan tinggi silinder pori , faktor lain yang berpengaruh terhadap debit infiltrasi adalah jarak silinder pori, dimana semakin besar jarak silinder pori semakin kecil debit infiltrasi yang terjadi pada Saluran drainase Bersilinder Pori, hal ini ditunjukkan secara jelas pada Gambar (4), (5) dan (6).

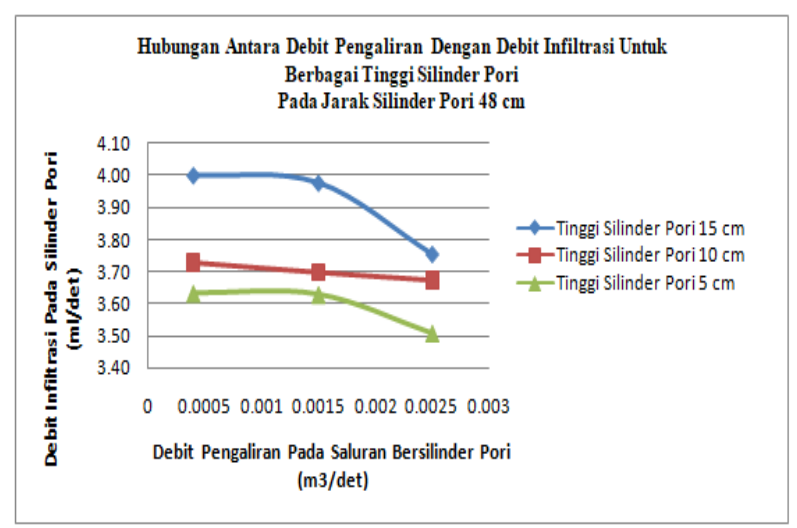

Gambar 4. Pengaruh Debit Pengaliran Terhadap Debit Infiltrasi 


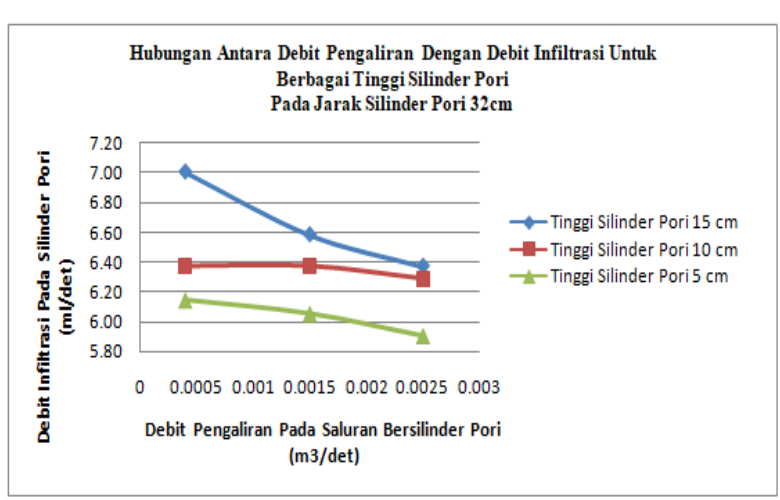

Gambar 5. Pengaruh Debit Pengaliran Terhadap Debit Infiltrasi

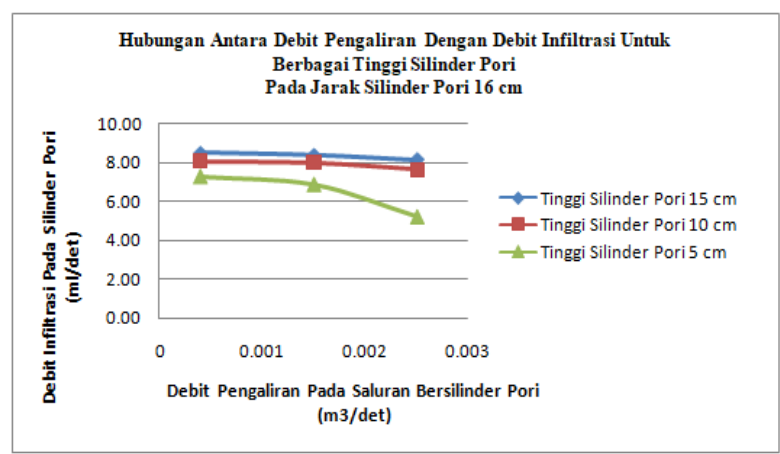

Gambar 6. Pengaruh Debit Pengaliran Terhadap Debit Infiltrasi

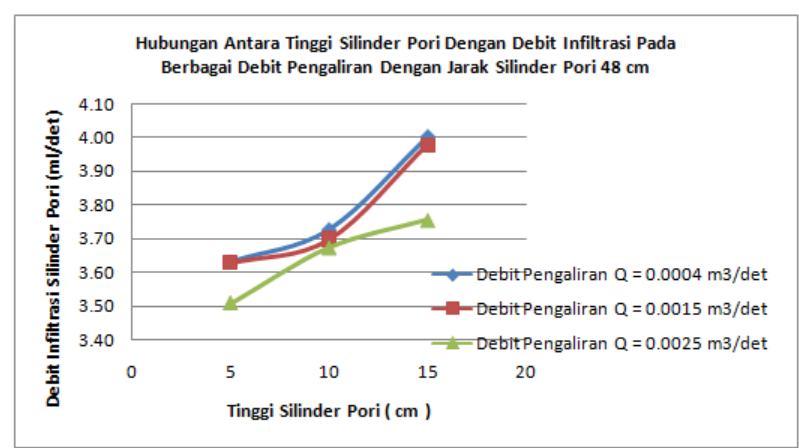

Gambar 7. Pengaruh Debit Pengaliran Terhadap Debit Infiltrasi

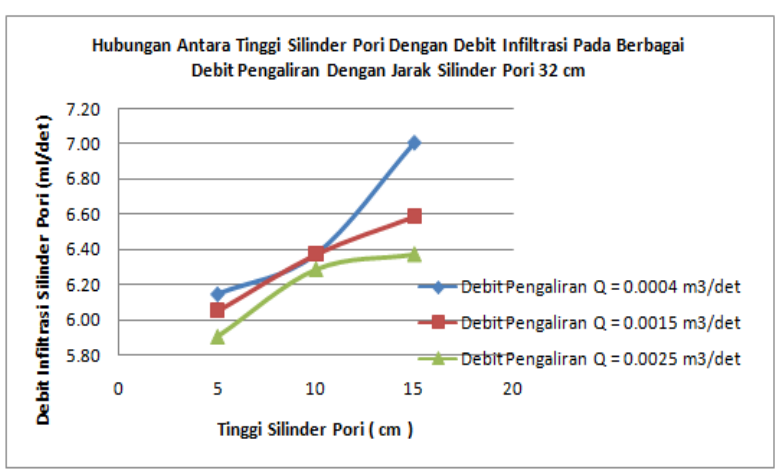

Gambar 8. Pengaruh Debit Pengaliran Terhadap Debit Infiltrasi

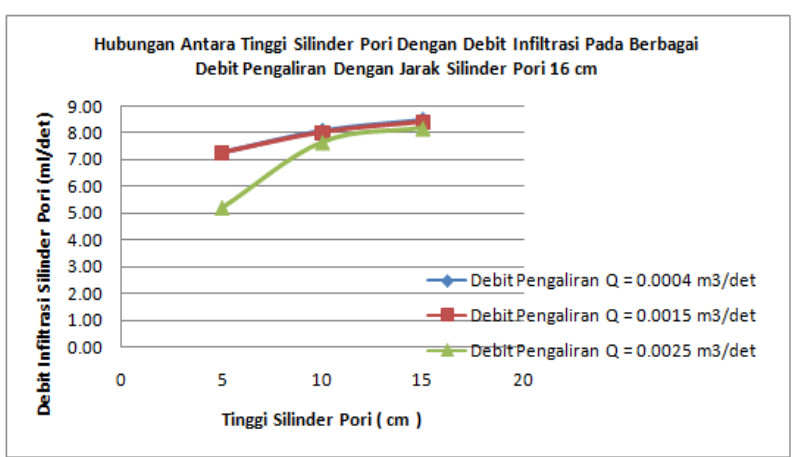

Gambar 9. Pengaruh Debit Pengaliran Terhadap Debit Infiltrasi

\section{KESIMPULAN}

Untuk daerah dengan tekstur tanah lempung, infiltrasi air kedalam lapisan tanah dapat dilakukan dengan membuat Saluran Drainase Bersilinder Pori. Rasio Silinder Pori dipengaruhi oleh besarnya air yang akan diinfiltrasikan ke dalam lapisan tanah.

\section{DAFTAR PUSTAKA}

Daud F.S., Selintung, M, Thaha Arsyad.2012 Uji Besaran dan Posisi Pori Pada Drainase Jalan Raya Terhadap Overland Flow. Prosiding Konfrensi Nasional Pasca Sarjana Teknik Sipil (KNPTS) 2012 : TSA- 55 - TSA 56.

Daud F.S., Selintung,M, Thaha Arsad.2013 The effect of soil texture and pore dimention of road drainage on surface flow reduction. Proceeding the 6 th Civil Engineering Conference in Asia Region . 2013 :ISBN 978-602-08-03.

Daud F.S., Selintung,M, Thaha Arsad.2013 Pore drainage influent on channel dimensions against infiltration in static conditions. Proceeding International Seminar on Applied Technology, Science and Art, 2013.

Daud F.S., Selintung,M, Thaha Arsad.2012 Uji Besaran dan Posisi Pori Pada Drainase Jalan Raya Terhadap Overland Flow. Prosiding Konfrensi Nasional Pasca Sarjana Teknik Sipil (KNPTS) 2012 : TSA- 55 - TSA 56.

Dariah A, Rachman A. 2006. Pengukuran Infiltrasi Balittanah.litbang.pertanian.go.id/Ind/doku mentasi/buku

Hakim Duppa, Reduksi Aliran Permukaan Dengan Resapan Berpori Pada Daerah Genangan, Makassar. Indonesia.

Hary Pradiko,dkk. 2017. Model penerapan Drainase Berwawasan Lingkungan Skala Individu di lahan Permukiman kawasan bandung Utara., Jurnal Teknik Sipil, Vol 24 - 2017, hal 8390

I Ketut Suharta. 2000. Mengetahui kapasitas infiltrasi dan kapasitas perlokasi dan mengetahui potensi peresapan air hujan di wilayah Kota Denpasar. Indonesia

Goldsmith. 1993:162 dalam Sucipto dan Agung 
Sutarto, 2007, Jurnal Teknik Sipil \& Perencanaan, Nomor 1 Volume 9 - Januari 2007, hal $33-42$.

Michal Sněhota et.al. 2010. Preferential and Unstable Flow: From The Pore To The Catchment Scale. Germany.

Pangeran H S, Sistim Permodelan dan Perencanaan drainase. 2018. https://www.slideshare.net/PangeranSitorus/ paper-sistem-pemodelan-dan-perencanaandrainase. 31 Juli 2018.

Peter R Jørgensen. 2004. Monitoring well interception with fractures in clayey till

Salem Bouri, Hamed Ben Dhia. 2009. A thirty-year artificial recharge experiment ina coastal aquifer in an arid zone: The Teboulba aquifer system (Tunisian Sahel), Laboratoire 3E, ENIS, BP W 3038, Sfax, Tunisia, Surface geosciences (HydrologyHydrogeology), Elsevier, Published by Elsevier Masson SAS.

Rumillah H, Kemala J, Bambang. Sistim Drainase Sebagai Pengendalian Banjir Kota Medan. 2014. Jurnal Penelitian Saintika, Vol 14 nomor 1, 2014.

Sunjoto.S. 2011. Comparison of Recharge System Formulas from Point of View of Dimension Analysis, Mathematical Logic and Flow Condition, Proceedings of the $4^{\text {th }}$ ASEAN Civil Engineering Conference, Department of Civil \& Environmental Engineering Gadjah Mada University, Yogyakarta, Indonesia 